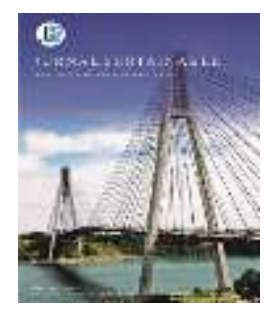

\title{
Penerapan Self Organizing Maps (SOM) dan Radial Basis Function (RBF) untuk Memprediksi Kecepatan Angin di Perairan Kota Tanjungpinang
}

\author{
Rini Hervianti Julia ${ }^{1}$, Nerfita Nikentari ${ }^{2, *}$, Nurul Hayaty ${ }^{3}$ \\ 1,2,3 Jurusan Informatika, Fakultas Teknik, Universitas Maritim Raja Ali Haji \\ 1,2,3 Jl. Politeknik Senggarang, Tanjungpinang 29100 \\ *Corresponding Author: nerfita.nikentari@gmail.ac.id
}

\begin{abstract}
Wind is very important role in human life, one of them for fishermen, natural conditions play an important role in the fluency of their activities, especially for the people of Tanjungpinang who lived in coastal areas as fishermen. But it will be a problem if the winds move with high intensity that will impact bad weather. To be able to monitor the movement of wind speed, this study made predictions using the method Self Organizing Maps (SOM) and Radial Basis Function (RBF) to predict wind speed. In this study the data used for daily wind speed prediction starts from January 2014 - October 2017. The results of the tests conducted with the 418 of data, the number of clusters obtained 33 from the training process produce 1,51 of RMSE and $28.98 \%$ of MAPE and $71,02 \%$ of accuracy . Keywords - Prediction, Wind Speeds, Radial Basis Function.
\end{abstract}

Intisari- Angin sangat berperan penting dalam kehidupan manusia, salah satunya bagi nelayan, kondisi alam berperan penting dalam kelancaran aktifitas mereka, khususnya masyarakat Tanjungpinang yang tinggal di daerah pesisir yang bermata pencaharian sebagai nelayan. Namun akan menjadi masalah apabila angin bergerak dengan intensitas yang tinggi yang akan berdampak cuaca buruk. Untuk dapat memantau pergerakan kecepatan angin, penelitian ini melakukan prediksi menggunakan metode Self Organizing Maps (SOM) dan Radial Basis Function (RBF) untuk memprediksi kecepatan angin. Dalam penelitian ini data yang digunakan untuk prediksi kecepatan angin harian dimulai dari Januari 2014 - Oktober 2017. Hasil pengujian yang dilakukan dengan data sebanyak 418, jumlah cluster yang didapat dari proses pelatihan sebanyak 33 menghasilkan RMSE sebesar 1,51 dan MAPE $28.98 \%$ serta akurasi sebesar 71,02\%.

Kata kunci-Prediksi, Kecepatan Angin, Radial Basis Function.

\section{Pendahuluan}

Kepulauan Riau (KEPRI) merupakan salah satu provinsi di Indonesia yang memiliki luas wilayah $252.601 \mathrm{~km}^{2}$, dengan luas lautan sebesar 95\%. Dengan wilayah tersebut KEPRI memiliki 5 kabupaten dan 2 kota. Selain itu, provinsi KEPRI juga berdekatan dengan 2 negara yaitu
Malaysia dan Singapura. Posisi geografis yang sangat dekat dan dikelilingi laut membuat daerah - daerah di Kepulauan Riau sangat bergantung dengan aktivitas baharinya. Sebagian masyarakat Tanjungpinang yang tinggal di daerah pesisir bermata pencaharian sebagai nelayan yang memanfaatkan hasil alam untuk memenuhi kebutuhan hidup mereka, ada pula yang 
menyewa jasa perahu untuk penyebrangan antar pulau. Tentu saja untuk kelancaran aktifitas mereka alam sangat berperan penting, terutama angin dan kondisi laut. Angin merupakan elemen dari alam yang tidak dapat dipisahkan dari kehidupan manusia, angin juga sangat berperan penting pada tumbuhan untuk proses penyerbukan, hewan sebagai stabilitas hidup mereka. Seperti burung yang memanfaatkan angin untuk terbang. Namun yang menjadi permasalahan ialah apabila angin tersebut bergerak dengan intensitas sangat tinggi, tentulah menjadi ancaman bagi alam yang berdampak pada cuaca buruk, efek yang terjadi bisa saja gelombang tinggi yang akan menyulitkan nelayan untuk melaut. Para nelayan sampai saat ini masih menggunakan cara lama untuk memperkirakan kecepatan angin yang terjadi pada saat itu dengan melihat awan ataupun merasakan arah angin serta melihat bulan, sehingga mereka dapat memutuskan untuk berlayar atau tidak. Karena untuk memperkirakan angin yang akan terjadi masih dilakukan secara manual, untuk itu dibutuhkan lah sebuah sistem yang nantinya akan memprediksi kecepatan angin yang akan datang dengan menerapkan model atau metode yang tepat untuk menunjang hasil prediksi tentunya sistem diharapkan dapat mempermudah nelayan. Prediksi kecepatan akan menerapkan metode Self Organizing Maps (SOM) yang akan di kombinasikan dengan Radial Basis Function $(R B F)$.

\section{METODE PENELITIAN}

\section{A. Normalisasi dan Denormalisasi}

Sebelum melakukan pelatihan dalam sistem data input dan data uji akan di normalisasi. Normalisasi bertujuan untuk mendapatkan data dengan ukuran yang lebih kecil yang mewakili data asli tanpa kehilangan karakteristi sendirinya. Rumus dari normalisasi yaitu ; [1]

$$
\text { normalisasi }=\left(\frac{x-\min }{\max -\min }\right)
$$

Keterangan :

$$
\begin{array}{ll}
\mathrm{X} & =\text { Data } \\
\text { Min } & =\text { Data Minimum } \\
\text { Max } & =\text { Data Maximum }
\end{array}
$$

Sedangkan denormalisasi adalah mengembalikan ukuran data yang telah dinormalisasi sebelumnya untuk mendapatkan data yang asli. Denormalisasi dilakukan pada hasil keluaran dari pelatihan. Adapun rumus dari normalisasi yaitu sebagai berikut ; [1]

denormalisasi $=Y \times(\max -\min )+\min$

Keterangan ;

$\mathrm{Y}=$ Output keluaran

Max = Data maximum

Min $=$ Data minimum

\section{B. Self Organizing Maps (SOM)}

Self Organizing Maps (SOM) memiliki Jaringan Kohonen yang diperkenalkan oleh Teuvo Kohonen seorang ilmuwan Finlandia pada tahun 1982 dan kelas khusus dari jaringan syaraf tiruan [2].

[3] Algoritma pada jaringan Self Organizing Maps adalah sebagai berikut ;

0. Inisialisasi bobot Wij. atur parameter derajat pembelajaran

1. Selama kondisi berhenti masih salah, lakukan langkah 2-8

2. Untuk setiap vektor masukan $x$, lakukan langkah 3-5

3. Untuk setiap j hitung jarak Euclidean

$$
D(j)=\Sigma\left(W_{i j}-X_{i}\right)^{2}
$$

4. Temukan indeks $J$ sehingga $D(j)$ minimum

5. Untuk setiap unit $j$ yang termasuk di dalam tetangga dari $j$, dan untuk setiap $i$;

$$
W_{i j}(t+1)=W_{i j}(t)+\alpha(t)\left[X_{i}-W_{i j}(t)\right]
$$

6. Perbaiki nilai rata pembelajaran $\alpha$ (learning rate)

Tiap kenaikan epoch (iterasi) maka ; [4]

learning rate $=$ learning rate awal $* 0,5$

7. Kurangi radius tetangga topologis pada waktu yang sudah ditentukan (epoch)

8. Tes kondisi berhenti

Kriteria pemberhentian bisa berupa pembatasan jumlah iterasi, atau ketika learning rate $=0$ [2].

\section{Radial Basis Function (RBF)}

Model yang akan dibangun untuk melakukan prediksi kecepatan angin yaitu model jaringan dengani nput node, hidden node, dan 1 output node. Arsitektur jaringan RBF yang akan 
dibangun untuk prediksi kecepatan angin dapat dilihat pada gambar 1 ;

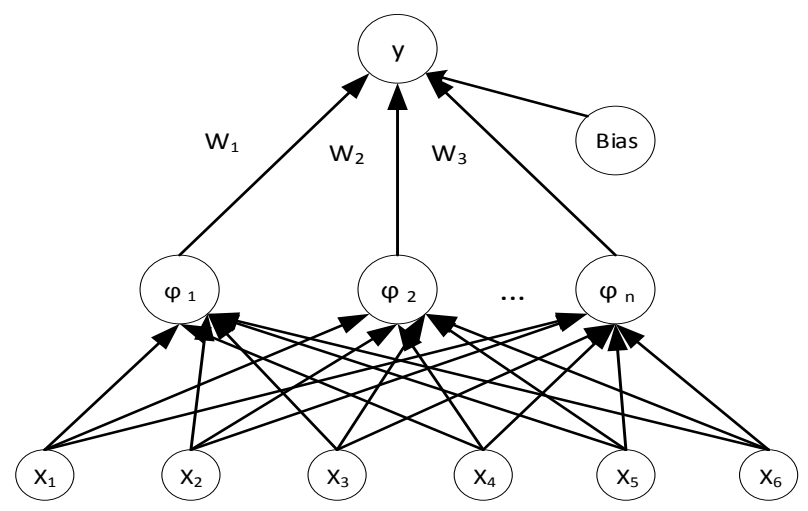

Gambar 1. Arsitektur Jaringan untuk prediksi Kecepatan Angin

Algoritma pelatihan jaringan syaraf tiruan RBF, [3] ;

1. Pengelompokkan data. Pada tahap ini data dikelompokkan kedalam beberapa cluster data berdasarkan tingkat kemiripan ciri antar data tersebut. Untuk melakukan pengelompokkan data berdasarkan kemiripan ciri dari masingmasing data tersebut dan kemudian menghasilkan pusat/center dari kelompokkelompok data tersebut. Pada tahap ini proses clustering bersifat unsupervised.

2. Pembaharuan bobot. Jaringan syaraf tiruan menyimpan pengetahuannya dalam bentuk bobot neuron-neuronnya. Pelatihan tahap berikutnya berfungsi mendapatkan nilai bobot neuron-neuronnya. Pada tahap ini serangkaian perhitungan yang di perlukan untuk memperbarui nilai bobot membutuhkan data training beserta targetnya, jadi proses pelatihannya bersifat supervised. Langkah langkahnya ;

a. Meneruskan sinyal input ke hidden layer dan menghitung nilai fungsi aktivasi pada setiap hidden layer menggunakan rumus $\phi(r)=r^{2} \ln (r)$

Dengan :

$\mathrm{r}$ = Jarak Euclidean antara pusat pada suatu neuron dilapisan tersembunyi dengan vektor input [5]

$$
r=\sqrt{\left(x_{i k}-w_{j k}\right)^{2}}
$$

Dimana ; $\mathrm{r}=$ Jarak antara data input ke center

$\mathrm{x}=$ data

$\mathrm{w}=$ bobot baru

b. Menyusun matriks Gaussian dari hasil perhitungan pada langkah (a

$$
G=\left[\begin{array}{cccc}
\emptyset 11 & \emptyset 12 & \cdots & \emptyset 1 C \\
\emptyset 21 & \emptyset 22 & \cdots & \emptyset 2 C \\
\cdots & \cdots & \cdots & \cdots \\
\emptyset M 1 & \emptyset M 2 & \cdots & \emptyset M C
\end{array}\right]
$$

$$
\begin{array}{ll}
\mathrm{M} & =\text { Vektor input ke }-\mathrm{M} \\
\mathrm{C} & =\text { hidden unit ke-C }
\end{array}
$$

c. Menghitung bobot baru (W) dengan mengalikan pseudoinverse dari matriks $G$ dengan vektor target (d) dari data training

$$
\begin{aligned}
W & =G^{+} d \\
& =\left(\left(G^{T} G\right)\right)^{-1} G^{T} d
\end{aligned}
$$

Keterangan :

$$
\begin{aligned}
& \mathrm{W}=\text { bobot } \\
& \mathrm{G}^{+}=\text {pseudoinverse } \\
& \mathrm{d}=\text { target } \\
& \mathrm{G}^{\mathrm{T}}=\text { matriks transpose } \\
& \left(\mathrm{G}^{\mathrm{T}} \mathrm{G}\right)^{-1}=\text { matriks inverse }
\end{aligned}
$$

d. Menghitung nilai ouput dari jaringan syaraf tiruan [6]

$$
\begin{aligned}
y(x)= & \sum_{j=1}^{m} \mathrm{~W}_{j} h_{j}(\mathrm{x})+\mathrm{b} \\
\mathrm{y} & =\text { Output } \\
\mathrm{W}_{\mathrm{j}} & =\text { Bobot ke- } \mathrm{j} \\
h_{\mathrm{j}} & =\text { Fungsi aktivasi ke- } \mathrm{j} \\
\mathrm{b} & =\text { bias } \\
\mathrm{m} & =\text { Banyak data }
\end{aligned}
$$

\section{Menghitung Error}

Untuk melihat hasil dari prediksi menggunakan metode RBF apakah cocok dengan data aktual perlu dihitung Root Means Square Error (RMSE) dan Mean 
Absolout Percentage Error (MAPE), apabila RMSE dan MAPE memperoleh nilai yang kecil maka hasil pelatihan digunakan untuk memprediksi nilai data kedepannya. Adapun persamaan RMSE adalah sebagai berikut ; [7]

$$
\text { RMSE }=\sqrt{\frac{1}{N} \sum_{i=1}^{N}\left(X_{i}-\hat{X}_{i}\right)^{2}}
$$

Dimana :

$$
\begin{aligned}
& \mathrm{N}=\text { Jumlah data } \\
& \mathrm{X}=\text { Data Aktual } \\
& \hat{X}=\text { Data hasil prediksi }
\end{aligned}
$$

Adapun rumus MAPE yang digunakan adalah sebagai berikut.; (Sari., 2017)

$$
\begin{aligned}
\text { MAPE } & =\frac{\sum \frac{\mid \text { Aktual-Prediksi } \mid}{\text { Aktual }} \times 100}{n} \\
\mathrm{n} & =\text { jumlah data }
\end{aligned}
$$

\section{HASIL DAN PEMBAHASAN}

Data yang digunakan pada penelitian ini yaitu data kecepatan angina harian dalam kurun waktu 4 tahun, dimulai dari 1 Januari 2014 sampai dengan 23 Oktober 2017 dimana data tersebut dibagi menjadi 2 bagian data yaitu, data pelatihan dan data pengujian. Data pelatihan digunakan untuk melakukan proses pelatihan pada data yang nantinya pada proses pelatihan bertujuan untuk mendapatkan bobot yang diharapkan. Setelah mendapatkan bobot dari proses pelatihan, bobot tersebut akan digunakan untuk melakukan proses pengujian dengan data yang berbeda pada saat proses pelatihan. Variabel data yang digunakan berupa data kecepatan angin pada hari - hari sebelumnya. Sedangkan variabel data keluaran yang diharapkan berupa kecepatan angin pada hari berikutnya.

Variabel yang digunakan pada penelitian ini yaitu 6 hari data kecepatan angina dan untuk keluaran yaitu kecepatan angin pada hari ke 7 . Banyaknya data yang digunakan untuk penelitian ini yaitu sebanyak 1.392 data, dimana untuk pelatihan digunakan 974 data dan untuk pengujian digunakan 418 data.
Untuk mendapatkan hasil prediksi kecepatan angin yang akurat dilakukan pelatihan berkali - kali dengan cara mengubah jumlah cluster, dan learning rate. Data yang digunakan pada percobaan ini menggunakan data sebanyak 974 sebagai data training dan 418 sebagai data testing dengan percobaan jumlah neuron input 6 , iterasi 100 , learning rate 0,1 sampai 0,9 dan jumlah cluster.

Adapun hasil dari percobaan dengan mencari cluster yang akan digunakan dapat dilihat pada tabel 1 .

Tabel 1. Hasil pelatihan dengan jumlah cluster

\begin{tabular}{ccccc}
\hline & & & RMSE & MAPE \\
No & Cluster & Iterasi & Training & Training \\
\hline 1 & 3 & 100 & 1,58 & $25,29 \%$ \\
2 & 4 & 100 & 1,59 & $25,42 \%$ \\
3 & 5 & 100 & 1,57 & $25,14 \%$ \\
4 & 6 & 100 & 1,57 & $25,02 \%$ \\
5 & 7 & 100 & 1,57 & $25,11 \%$ \\
6 & 8 & 100 & 1,57 & $25,02 \%$ \\
7 & 9 & 100 & 1,57 & $25,1 \%$ \\
8 & 10 & 100 & 1,58 & $25,05 \%$ \\
9 & 11 & 100 & 1,57 & $25,04 \%$ \\
10 & 12 & 100 & 1,57 & $25,01 \%$ \\
11 & 13 & 100 & 1,56 & $24,81 \%$ \\
12 & 14 & 100 & 1,56 & $24,8 \%$ \\
13 & 15 & 100 & 1,56 & $24,82 \%$ \\
14 & 16 & 100 & 1,55 & $24,36 \%$ \\
15 & 17 & 100 & 1,56 & $24,79 \%$ \\
16 & 18 & 100 & 1,54 & $24,61 \%$ \\
17 & 19 & 100 & 1,55 & $24,5 \%$ \\
18 & 20 & 100 & 1,56 & $24,86 \%$ \\
19 & 21 & 100 & 1,55 & $24,62 \%$ \\
20 & 22 & 100 & 1,55 & $24,72 \%$ \\
21 & 23 & 100 & 1,55 & $24,56 \%$ \\
22 & 24 & 100 & 1,54 & $24,35 \%$ \\
23 & 25 & 100 & 1,54 & $24,36 \%$ \\
24 & 26 & 100 & 1,54 & $24,36 \%$ \\
25 & 27 & 100 & 1,54 & $24,44 \%$ \\
26 & 28 & 100 & 1,54 & $24,48 \%$ \\
27 & 29 & 100 & 1,54 & $24,58 \%$ \\
28 & 30 & 100 & 1,53 & $24,36 \%$ \\
29 & 31 & 100 & 1,54 & $24,38 \%$ \\
30 & 32 & 100 & 1,53 & $24,46 \%$ \\
31 & 33 & 100 & 1,52 & $23,81 \%$ \\
32 & 34 & 100 & 1,52 & $24,06 \%$ \\
\hline & & & & \\
\hline
\end{tabular}


Tabel 2. Lanjutan hasil pelatihan dengan jumlah

\begin{tabular}{ccccc}
\hline & & & RMSE & MAPE \\
No & Cluster & Iterasi & Training & Training \\
\hline 33 & 35 & 100 & 1,52 & $24,15 \%$ \\
34 & 36 & 100 & 1,52 & $24,07 \%$ \\
35 & 37 & 100 & 1,52 & $23,83 \%$ \\
36 & 38 & 100 & 1,66 & $26,5 \%$ \\
37 & 39 & 100 & 2 & $31,4 \%$ \\
\hline
\end{tabular}

Dari percobaan pada Tabel 1 dan 2, dapat dilihat bahwa pelatihan terbaik berupa nilai RMSE terkecil yang terletak pada data sampel yang dilatih dengan jumlah cluster 33 dengan iterasi 100 dan mendapat hasil RMSE dan MAPE training sebesar 1,52 dan 23.81\%.

Tahap selanjutnya dilakukan proses pengujian dengan menggunakan data testing. Hasil prediksi kecepatan angin pada proses pengujian dapat dilihat pada tabel 3 .

Tabel 3. Hasil Data Testing

\begin{tabular}{ccc}
\hline No & Target & Prediksi \\
\hline 1 & 6 & 4,96 \\
2 & 6 & 4,79 \\
3 & 5 & 4,48 \\
4 & 4 & 4,99 \\
5 & 7 & 5,11 \\
6 & 7 & 5,48 \\
7 & 6 & 6,19 \\
8 & 4 & 5,72 \\
9 & 5 & 5,51 \\
10 & 5 & 5,45 \\
11 & 7 & 5,84 \\
12 & 7 & 6 \\
13 & 7 & 5,48 \\
14 & 6 & 5,57 \\
15 & 5 & 6,08 \\
16 & 4 & 5,91 \\
17 & 4 & 5,97 \\
18 & 5 & 5,6 \\
19 & 4 & 5,49 \\
20 & 4 & 5,07 \\
$:$ & $:$ & $:$ \\
411 & 4 & 5,08 \\
\hline & &
\end{tabular}

Dari tabel 3 proses pengujian dengan menggunakan data testing menghasilkan RMSE dan MAPE sebesar 1,51 dan 28,98\% dengan akurasi sebesar $71,02 \%$.

$$
\begin{gathered}
\operatorname{RMSE}=\sqrt{\frac{(6-4,96)^{2}+(6-4,79)^{2}+\ldots+\cdots+(4-5,08)^{2}}{411}} \\
=1,51
\end{gathered}
$$$$
\begin{aligned}
\text { MAPE } & =\frac{\sum \frac{[(6-4,96)}{6}+\frac{(6-4,59)}{6}+\ldots+\frac{(4-5,08)]}{4} X 100}{411} \\
& =28.98 \%
\end{aligned}
$$

Untuk melihat hasil perbandingan dari pengujian untuk data aktual dan data prediksi kecepatan angin dapat dilihat pada gambar 2 .

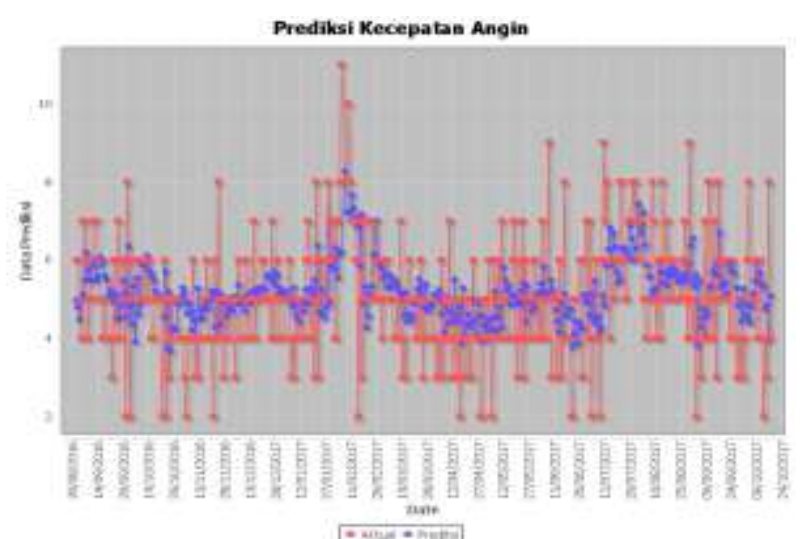

Gambar 2. Grafik Hasil Prediksi Kecepatan Angin

\section{KESIMPULAN}

Kesimpulan yang dapat diambil dari penelitian ini adalah sebagai berikut ;

1. Penelitian ini menunjukkan bahwa metode Self Organizing Maps (SOM) dan Radial Basis Function (RBF) dapat digunakan untuk prediksi

2. Berdasarkan hasil proses pelatihan dengan percobaan menggunakan jumlah cluster, pola data prediksi terbaik didapatkan dengan jumlah 33 cluster yang menghasilkan RMSE sebesar 1,52 dan MAPE 23,81\% dengan akurasi $76,19 \%$.

\section{REFERENSI}

[1] Indrabayu., Harun, N., Pallu, S.M., Achmad, A., Fikha, C.L., 2012, "Prediksi 
Curah Hujan Dengan Jaringan Saraf Tiruan". Universitas Hasanuddin.

[2] Larose, D., T., 2004, Discovering Knowledge in Data; An Introduction to Data Mining. USA:John Wiley\&Sons Inc.

[3] Benni, A., N., 2012, Peramalan harga emas menggunakan jaringan syaraf tiruan Self Organizing Maps dan Radial Basis Function, Teknik Informatika, Politeknik Kediri.

[4] Rahmawati. D., Cahyani, D.A., Putro, S. S., 2015, Pemanfaatan Metode Cluster SOM - IDB sebagai Analisa Pengelompokan Penerimaan Beasiswa, Fakultas Teknik, Universitas Trunojoyo, 2015.
[5] Haykin, S., 2009, Neural Networks and Learning Machines. Third Edition, Pearson International Edition:New Jersey.

[6] Fajarianti, C., dkk., 2017, Proceeding of Forecasting of PT.PLN (Persero) Revenue Using Radial Basis Function Neural Network, AIP Conference Proceeding, Universitas Padjajaran, Indonesia

[7] Soesanto, Oni., Eko, A., Turianto, D., 2015, Optimasi Learning Radial Basis Function Neural Network dengan Extended Kalman Filter, Universitas Lambung Mangkurat. September 2015, Vol. 03, No. 2. ISSN 2406-7857 